\title{
The P-glycoprotein inhibitor quinidine decreases the threshold for bupivacaine-induced, but not lidocaine-induced, convulsions in rats
}

\author{
La quinidine, un inbibiteur de P-glycoprotéine, abaisse le seuil des convulsions \\ induites par la bupivacaïne, mais non par la lidocaine, chez les rats
}

Tomoharu Funao MD, Yutaka Oda MD, Katsuaki Tanaka MD, Akira Asada MD

Purpose: To examine whether inhibition of P-glycoprotein (P-gp) activity by quinidine affects the central nervous system toxicity of lidocaine and racemic bupivacaine (bupivacaine).

Methods: Forty male Sprague-Dawley rats were randomly divided into four groups $(n=10)$. Fifteen minutes following administration of $15 \mathrm{mg} \cdot \mathrm{kg}^{-1}$ of quinidine (QL and QB groups) or saline ( $\mathrm{L}$ and $\mathrm{B}$ groups), lidocaine ( $\mathrm{L}$ and $\mathrm{QL}$ groups, $\left.4 \mathrm{mg} \cdot \mathrm{kg}^{-1} \cdot \mathrm{min}^{-1}\right)$ or bupivacaine (B and QB groups, I $\mathrm{mg} \cdot \mathrm{kg}^{-1} \cdot \mathrm{min}^{-1}$ ) was infused until convulsions occurred. Concentrations of lidocaine and its primary metabolite, monoethylglycinexylidide (MEGX) and bupivacaine in plasma and in the brain at the onset of convulsions were measured by high-performance liquid chromatography.

Results: There were no differences in the dose of lidocaine required to induce convulsions between the $\mathrm{L}$ and $\mathrm{QL}$ groups. There were no differences in the concentrations of total $(L=17.2$ $\left.\pm 3.5, \mathrm{QL}=16.6 \pm 2.6 \mu \mathrm{g} \cdot \mathrm{mL}^{-1}\right)$ or unbound lidocaine $(\mathrm{L}=7.8$ $\left.\pm 2.5, \mathrm{QL}=7.3 \pm 2.3 \mu \mathrm{g} \cdot \mathrm{mL}^{-1}\right)$, total $(\mathrm{L}=1.2 \pm 0.5, \mathrm{QL}=1.3$ $\left.\pm 0.7 \mu \mathrm{g} \cdot \mathrm{mL}^{-1}\right)$ or unbound MEGX $(\mathrm{L}=0.9 \pm 0.5, \mathrm{QL}=0.8 \pm$ $\left.0.4 \mu \mathrm{g} \cdot \mathrm{mL}^{-1}\right)$ in plasma, total lidocaine or MEGX in the brain at the onset of convulsions between the $L$ and $Q L$ groups. The dose of bupivacaine required to induce convulsions was comparable in the $\mathrm{B}$ and $\mathrm{QB}$ groups. At the onset of convulsions, plasma concentrations of both total $\left(B=4.9 \pm 1.1, Q B=4.0 \pm 0.6 \mu \mathrm{g} \cdot \mathrm{mL}^{-1}, P=\right.$ $0.03)$ and unbound bupivacaine $(B=1.4 \pm 0.6, Q B=0.9 \pm 0.2$ $\mu \mathrm{g} \cdot \mathrm{mL}^{-1}, P=0.02$ ) were significantly lower in the $\mathrm{QB}$ group than in the B group. There were no differences in concentration of total bupivacaine in the brain between the B and QB groups.

Conclusion: These results suggest that quinidine inhibited P-gP activity, resulting in increased brain/plasma concentration ratio of bupivacaine, but not of lidocaine, and decreased the threshold of plasma concentration for bupivacaine-induced convulsions.
Objectif : Vérifier si l'inhibition de l'activité des P-glycoprotéines (P-gp) par la quinidine agit sur la toxicité de la lidocaïne et de la bupivacaïne racémique (bupivacaïne) sur le système nerveux central.

Méthode : Quarante rats mâles Sprague-Dawley ont été répartis au hasard en quatre groupes $(n=10)$. Quinze minutes après l'administration de $15 \mathrm{mg} \cdot \mathrm{kg}^{-1}$ de quinidine (groupes $Q \mathrm{~L}$ et $Q B$ ) ou de solution saline (groupes $L$ et $B$ ), des perfusions de lidocaine (groupes $L$ et $Q L$, $4 \mathrm{mg} \cdot \mathrm{kg}^{-1} \cdot \mathrm{min}^{-1}$ ) ou de bupivacaine (groupes $B$ et $Q B, I$ $\mathrm{mg} \cdot \mathrm{kg}^{-1} \cdot \mathrm{min} \mathrm{l}$ ) ont été administrées jusqu'à l'apparition de convulsions. On a mesuré par chromatographie liquide haute performance les concentrations plasmatiques et cérébrales de lidocaïne, et de son principal métabolite, le monoéthylglycinexylidide (MEGX), et de bupivacaïne.

Résultats : La dose de lidocaïne nécessaire à l'induction des convulsions entre les rats des groupes $L$ et QL n'a pas présenté de différence. Aucune différence n'a été notée entre les concentrations plasmatiques de lidocaine totale $\left(L=17,2 \pm 3,5, Q L=16,6 \pm 2,6 \mu \mathrm{g} \cdot \mathrm{mL}^{-1}\right)$ et libre $\left(L=7,8 \pm 2,5, Q L=7,3 \pm 2,3 \mu g \cdot \mathrm{mL}^{-1}\right)$, entre le MEGX total $\left(L=1,2 \pm 0,5, Q L=1,3 \pm 0,7 \mu g \cdot \mathrm{mL}^{-1}\right)$ et libre $(L=0,9 \pm 0,5$, $\left.Q L=0,8 \pm 0,4 \mu \mathrm{g} \cdot \mathrm{mL}^{-1}\right)$, entre les concentrations cérébrales de lidocaine totale et de MEGX total, au déclenchement des convulsions chez les rats des groupes $L$ et QL. La dose de bupivacaïne nécessaire pour induire les convulsions a été comparable pour les rats des groupes $B$ et $Q B$. Au début des convulsions, les concentrations plasmatiques de bupivacaïne totale $\left(B=4,9 \pm 1,1, Q B=4,0 \pm 0,6 \mu \mathrm{g} \cdot \mathrm{mL}^{-1}, P=\right.$ $0,03)$ et libre $\left(B=1,4 \pm 0,6, Q B=0,9 \pm 0,2 \mu g \cdot \mathrm{mL}^{-1}, P=0,02\right)$ ont été significativement plus faibles dans le groupe $Q B$ que dans le groupe $B$. Aucune différence de concentration de bupivacaïne totale cérébrale n'a été notée entre les groupes $B$ et $Q B$.

Conclusion : La quinidine a inhibé l'activité de la P-gp, entraînant une hausse du ratio de la concentration cérébrale/plasmatique de bupiva-

From the Department of Anesthesiology and Intensive Care Medicine, Graduate School of Medicine, Osaka City University, Osaka, Japan. Address correspondence to: Dr. Yutaka Oda, Department of Anesthesiology and Intensive Care Medicine, Graduate School of Medicine, Osaka City University, 1-5-7 Asahimachi, Abeno-ku, Osaka 545-8586, Japan. Phone: 81-6-6645-2186; Fax: 81-6-6645-2489; E-mail: odayou@msic.med.osaka-cu.ac.jp

This study was supported in part by the Fund for Medical Research from Osaka City University Medical Research Foundation (2001) and by Grant-in-Aid for Research from the Ministry of Education, Science and Culture of Japan, Nos. 11671517 and 14571460. Accepted for publication March 10, 2003.

Revision accepted June 5, 2003. 
caïne, mais non de lidocaïne, et une baisse du seuil de concentration plasmatique pour les convulsions induites par la bupivacaïne. Les anesthésiques locaux sont couramment utilisés pour l'anesthésie régionale et le traitement de l'arythmie.

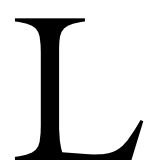

OCAL anesthetics are commonly used for regional anesthesia and treatment of arrhythmia. Accidental intravascular injection of a toxic dose of local anesthetics produces central nervous system (CNS) side effects such as dizziness, tremor and convulsions followed by cardiovascular collapse. ${ }^{1}$ To induce CNS toxicity, local anesthetics must diffuse into the brain across the blood brain barrier. Previous studies have shown that influx of globulinbound as well as free lidocaine into the brain is not prevented by the blood brain barrier. ${ }^{2}$ However, the blood brain barrier permeability of bupivacaine, a widely used long-acting local anesthetic with high lipid solubility and more than $90 \%$ protein binding, has not been examined.

The efflux pump P-glycoprotein (P-gp), a member of the adenosine triphosphate-binding cassette superfamily, was first identified in tumour cells by its ability to confer drug resistance to chemotherapeutic agents. ${ }^{3}$ $\mathrm{P}-\mathrm{gp}$ is found in various normal tissues including intestinal epithelium, liver canaliculi, renal tubules and bronchial epithelium. ${ }^{4}$ Importantly, P-gp is a vital component of the blood brain barrier capable of actively pumping a variety of drugs out of the CNS. ${ }^{5}$ Drugs transported by P-gp vary widely in structure. Relatively hydrophobic and amphipathic drugs, such as anticancer agents, steroid hormones, and calcium channel blocking agents, have been identified as P-gp substrates. ${ }^{4}$ Although the common structural feature of substrate compounds and the mechanism by which P-gp can recognize such diverse substrates are not fully understood, striking overlap of the substrates for cytochrome P450 (CYP) 3A and P-gp, and of their tissue distribution, has been observed, possibly due to coordinate regulation of CYP3A and P-gp gene expression. ${ }^{6}$ Amide-type local anesthetics including lidocaine, ropivacaine and bupivacaine are metabolized by CYP3A, ${ }^{7-9}$ suggesting that $\mathrm{P}$ gp might inhibit the expression of CNS toxicity of these local anesthetics by preventing the increase of their concentration in the brain.

Several drugs affect the CNS toxicity of local anesthetics. ${ }^{10,11}$ However, the effects of P-gp inducers or inhibitors on the CNS toxicity of local anesthetics remain unclear. Since local anesthetics are often used in combination with P-gp inhibitors such as verapamil, quinidine and cyclosporine, ${ }^{12-14}$ examining the effect of P-gp inhibitors on the CNS toxicity of local anes- thetics is important. In this study, we examined whether quinidine affects lidocaine- and bupivacaineinduced convulsions.

\section{Material and methods \\ Experimental procedure}

Following approval from the Institutional Animal Care and Use Committee, 40 male Sprague-Dawley rats aged nine weeks and weighing 320-360 g (CLEA Japan, Inc. Tokyo, Japan) were included in the study. Under general anesthesia with sevoflurane, the carotid artery was cannulated with a polyethylene catheter (PE 50, Becton Dickinson, Sparks, MD, USA) to monitor mean arterial blood pressure (MAP) and heart rate (HR) and for blood sampling. The cervical and femoral veins were cannulated with polyethylene catheters (SP31, Natsume, Tokyo, Japan) for infusion of drugs. These catheters were tunnelled subcutaneously to the posterior cervical region so that the animals could move freely. Before emergence from anesthesia, the animals were placed in a plastic container to recover for at least four hours before the experiment. Rectal temperature was maintained at $37^{\circ} \mathrm{C}$ with an infrared lamp. During that time, the arterial catheter was connected to a pressure transducer, and MAP and HR were recorded continuously on a polygraph (RM-6000, Nihon Kohden, Tokyo, Japan) connected to a computer. HR was monitored with a cardiotachometer triggered by the arterial pressure. The animals were randomly (by opening a sealed envelope) divided into lidocaine (L), quinidine and lidocaine $(\mathrm{QL})$, bupivacaine $(\mathrm{B})$, and quinidine and bupivacaine (QB) groups ( $n=10$, each group). Fifteen minutes after the iv injection of quinidine (15 $\mathrm{mg} \cdot \mathrm{kg}^{-1}, \mathrm{QL}$ and $\mathrm{QB}$ groups) or the corresponding volume of saline ( $\mathrm{L}$ and $\mathrm{B}$ groups), lidocaine ( $\mathrm{L}$ and QL groups, $4 \mathrm{mg} \cdot \mathrm{kg}^{-1} \cdot \mathrm{min}^{-1}$ ) or racemic bupivacaine (bupivacaine, B and QB groups, $1 \mathrm{mg} \cdot \mathrm{kg}^{-1} \cdot \mathrm{min}^{-1}$ ) was infused intravenously by an infusion pump (Model 1235, Atom, Tokyo, Japan) until convulsions occurred. The dose of quinidine to inhibit P-gp activity was determined based on a previous report. ${ }^{14} \mathrm{~A}$ bolus dose of ephedrine (10 $\mu \mathrm{g}, \mathrm{QL}$ and QB groups) or corresponding volume of saline ( $\mathrm{L}$ and $\mathrm{B}$ groups) was infused immediately after administration of quinidine, followed by a continuous infusion of ephedrine (10 $\mu \mathrm{g} \cdot \mathrm{min}^{-1}$, QL and QB groups) or the corresponding volume of saline ( $\mathrm{L}$ and $\mathrm{B}$ groups) to maintain MAP in the QL and QB groups at the same levels as in the $\mathrm{L}$ and $\mathrm{B}$ groups, respectively. In our preliminary study, neither $15 \mathrm{mg} \cdot \mathrm{kg}^{-1}$ of quinidine nor $10 \mu \mathrm{g}$ of bolus ephedrine followed by a continuous infusion of $10 \mu \mathrm{g} \cdot \mathrm{min}^{-1}$ induced convulsions. Observation of rats 
was performed by one of the authors (Y.O.), who was unaware of group assignment. A fine skeletal muscle twitching in the head and digits, which developed to general convulsions within approximately ten seconds was observed in all animals.

Arterial blood $(0.3 \mathrm{~mL})$ was drawn before infusion of saline or quinidine (baseline), before infusion of lidocaine or bupivacaine and at the onset of convulsions to determine blood gas tensions, $\mathrm{pH}$ and serum potassium levels. An additional $0.3 \mathrm{~mL}$ of blood was obtained in QL and QB groups before the infusion of lidocaine or bupivacaine to determine the plasma concentration of quinidine. At the onset of convulsions, an additional $0.5 \mathrm{~mL}$ of blood was obtained to measure the plasma concentrations of lidocaine and monoethylglycinexylidide (MEGX), a principal metabolite of lidocaine, or bupivacaine, immediately followed by the $i v$ infusion of pentobarbital (100 $\mathrm{mg} \cdot \mathrm{kg}^{-1}$ ) for euthanasia. The brain was perfused with $40 \mathrm{~mL}$ of ice-cold saline via a catheter inserted in the thoracic aorta and removed. Homogenate was made from the whole brain of each rat to determine the concentrations of lidocaine and MEGX or bupivacaine. Blood gas and electrolyte levels were measured immediately after sampling with a blood gas analyzer (ABL4, Radiometer, Copenhagen, Denmark). Remaining blood samples were centrifuged and plasma and brain samples were frozen and kept at $-80^{\circ} \mathrm{C}$ until analysis. Plasma concentrations of quinidine were measured by fluorescent polarization immunoassay (FLX, Abbott Laboratories, Abbott Park, IL, USA).

\section{Measurement of lidocaine, MEGX and bupivacaine in plasma and brain}

Plasma concentrations of total (protein-bound and unbound) lidocaine, MEGX and bupivacaine were determined by high-performance liquid chromatography (HPLC). Briefly, ropivacaine, an internal standard, and $\mathrm{Na}_{2} \mathrm{CO}_{3}$ and ethyl acetate were added to $150 \mu \mathrm{L}$ of plasma, vortexed and centrifuged. The supernatant was transferred to another tube containing $\mathrm{H}_{2} \mathrm{SO}_{4}$, vortexed and centrifuged. The aqueous layer was discarded and the residue was mixed with $\mathrm{NaOH}$ and evaporated to dryness. HPLC was carried out as described previously. ${ }^{15}$ Plasma concentrations of unbound lidocaine, MEGX and bupivacaine were measured using an ultrafiltration system (Centricon YM-30, Amicon, Inc., Beverly, MA, USA). Concentrations of local anesthetics in the brain were measured following the method of Yokoyama et $a l .{ }^{10}$ Regression coefficients of the calibration curves for lidocaine, MEGX and bupivacaine in plasma and brain were above 0.99 . The lower limits of quantitation were $1,0.1$, and $0.3 \mu \mathrm{g} \cdot \mathrm{mL}^{-1}$ for lidocaine, MEGX and bupi- vacaine in plasma, respectively, and 5, 0.5 and $1 \mu \mathrm{g} \cdot \mathrm{g}^{-1}$ tissue for lidocaine, MEGX and bupivacaine in the brain. Intra-assay and inter-assay variations were less than 7\% throughout the range of testing. Concentrations of lidocaine, MEGX and bupivacaine in plasma were the mean of duplicate measurements. Brain concentrations were the mean of triplicate measurements.

All values are expressed as mean \pm standard deviation. Statistical analysis was performed using StatView 5.0 (SAS Institute Inc. Cary, NC, USA). The number of animals in each of the four groups was determined based on our preliminary data in ten animals. We assumed that a $30 \%$ decrease of the plasma concentration of local anesthetic at the onset of convulsions would be important. Assuming a type I error protection of 0.05 and a power of 0.80 , nine to 11 animals in each group were required. Differences in convulsant doses of lidocaine or bupivacaine, concentrations of lidocaine, MEGX and bupivacaine in plasma and in the brain between the $\mathrm{L}$ and $\mathrm{QL}$ and $\mathrm{B}$ and $\mathrm{QB}$ groups were tested using an unpaired $t$ test. Two-way analysis of variance (ANOVA) for repeated measures was used to compare MAP, HR, arterial blood gas and plasma potassium levels before infusion of local anesthetics and at the onset of convulsions with baseline values within groups and corresponding values in the $\mathrm{L}$ and $\mathrm{QL}$ and $\mathrm{B}$ and $\mathrm{QB}$ groups. Where a post hoc test was used, Bonferroni correction was applied. Values were considered significant when $P<0.05$.

\section{Results}

The data set was complete for each rat entered in the study. There were no within group differences in arterial blood $\mathrm{pH}$ in either the $\mathrm{L}$ or QL groups, although $\mathrm{pH}$ at the onset of convulsions in the QL group was higher than in the $\mathrm{L}$ group $(7.47 \pm 0.05$ vs $7.44 \pm 0.03$, respectively, $P<0.05$ ). There were no differences in $\mathrm{PaCO}_{2}$ at the onset of convulsions between the $\mathrm{L}$ and QL groups. $\mathrm{PaO}_{2}, \mathrm{HCO}_{3}$ or potassium levels were within normal limits in both the L and QL groups during experiments. MAP was stable and there were no differences in MAP at baseline, before infusion of lidocaine, or at the onset of convulsions in either the $\mathrm{L}$ or QL groups. Plasma concentration of quinidine at the beginning of infusion of lidocaine was $1.7 \pm 0.5$ $\mu \mathrm{g} \cdot \mathrm{mL}^{-1}$ in the QL group. There were no differences in the cumulative doses of lidocaine required to induce convulsions between the L and QL groups (31.6 \pm 6.0 and $34.8 \pm 7.3 \mathrm{mg} \cdot \mathrm{kg}^{-1}$, respectively). There were no differences in concentrations of total and unbound lidocaine in plasma or total lidocaine in the brain between the L and QL groups (Figure 1). There were no differences in the concentration of total and 
unbound MEGX in plasma or total MEGX in the brain between these two groups either (Figure 2). The brain/plasma concentration ratios of total lidocaine at the onset of convulsions in the $\mathrm{L}$ and $\mathrm{QL}$ groups were $2.8 \pm 1.0$ and $2.3 \pm 0.9$, respectively $(P>0.05)$. The brain/plasma concentration ratios of total MEGX at the onset of convulsions in the $\mathrm{L}$ and QL groups were $1.9 \pm 0.5$ and $1.7 \pm 0.6$, respectively $(P>0.05)$.

Arterial blood $\mathrm{pH}$ at the onset of convulsions was significantly higher than baseline and before infusion of bupivacaine in both the $\mathrm{B}(7.48 \pm 0.03,7.44 \pm 0.02$, and $7.44 \pm 0.03$, respectively, $P<0.05)$ and $\mathrm{QB}(7.5 \mathrm{l}$ $\pm 0.03,7.44 \pm 0.04$, and $7.47 \pm 0.03$, respectively, $P<$ $0.05)$ groups. Also $\mathrm{PaCO}_{2}$ at the onset of convulsions was significantly lower than baseline and before infusion of bupivacaine in both the B $(27.8 \pm 2.8,34.9 \pm$ 2.7 , and $32.5 \pm 2.6$, respectively, $P<0.05)$ and $\mathrm{QB}$ $(27.8 \pm 3.9,34.8 \pm 2.8$, and $33.0 \pm 4.4$, respectively, $P$ $<0.05)$ groups. However there were no differences in $\mathrm{pH}$ or $\mathrm{PaCO}_{2}$ between these two groups during the experiments. $\mathrm{PaO}_{2}, \mathrm{HCO}_{3}$ or potassium levels were within normal limits in both the $\mathrm{B}$ and $\mathrm{QB}$ groups during the experiments. MAP was increased by the infusion of bupivacaine. MAP at the onset of convulsions was significantly higher than baseline and before infusion of bupivacaine in both the $\mathrm{B}(155 \pm 10,101 \pm 12$, and $109 \pm 10$, respectively, $P<0.05)$ and $\mathrm{QB}(150 \pm$ $10,109 \pm 11$, and $110 \pm 9$, respectively, $P<0.05)$ groups. However there were no differences in MAP between these two groups during the experiments. The plasma concentration of quinidine at the begin-
Total Lidocaine

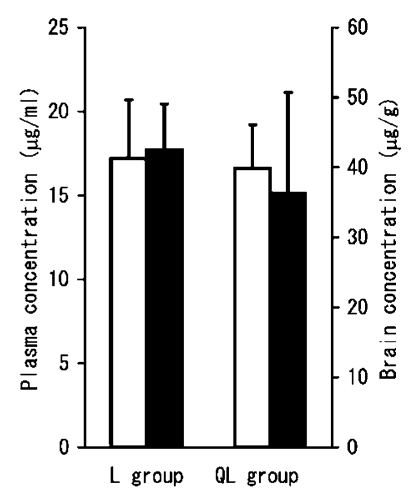

Unbound Lidocaine

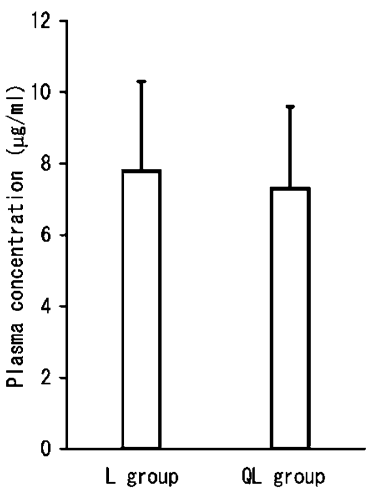

FIGURE 1 Concentrations of total (left) and unbound (right) lidocaine in plasma and brain at the onset of convulsions in the $\mathrm{L}$ and QL groups. Open columns = plasma concentration; filled columns $=$ brain concentration. Values are mean \pm standard deviation of ten experiments.

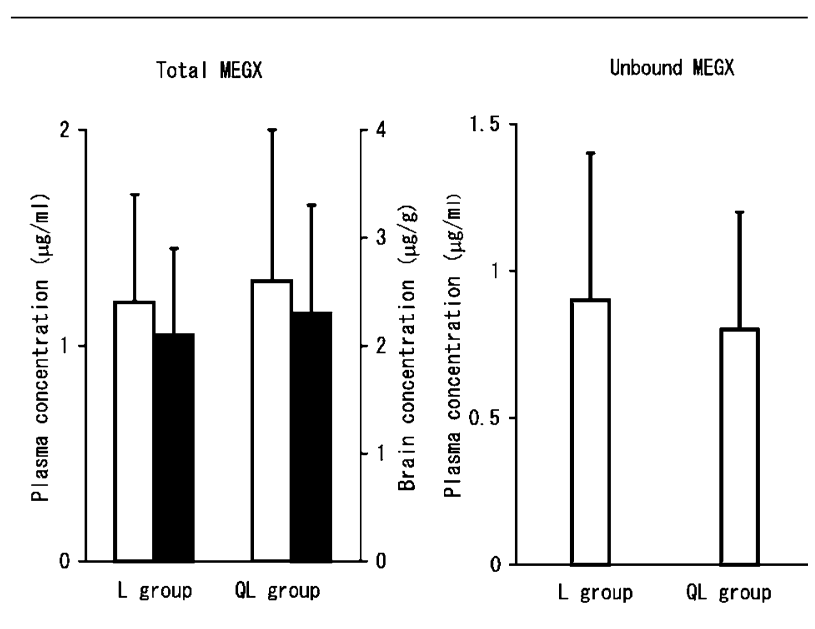

FIGURE 2 Concentrations of total (left) and unbound (right) monoethylglycinexylidide (MEGX) in plasma and brain at the onset of convulsions in the L and QL groups. Open columns = plasma concentration; filled columns $=$ brain concentration. Values are mean \pm standard deviation of ten experiments.

ning of infusion of bupivacaine was $1.7 \pm 0.2 \mu \mathrm{g} \cdot \mathrm{mL}^{-1}$ in the $\mathrm{QB}$ group, which was comparable to the value in the QL group. There were no differences in the cumulative doses of bupivacaine required to induce convulsions between the B and QB groups $(7.2 \pm 2.2$ vs 8.8 $\pm 1.6 \mathrm{mg} \cdot \mathrm{kg}^{-1}$, respectively). Plasma concentrations of both total and unbound bupivacaine were significantly lower in the $\mathrm{QB}$ group than in the $\mathrm{B}$ group at the onset of convulsions $(P=0.03$ and 0.02 , respectively; Figure $3)$. There were no differences in brain concentration of total bupivacaine between the $\mathrm{B}$ and $\mathrm{QB}$ groups (Figure 3). The brain/plasma concentration ratios of total bupivacaine in the $\mathrm{QB}$ group were significantly higher than those in the B group $(3.4 \pm 1.0$ vs $2.5 \pm$ 0.6 , respectively, $P=0.02$ ). In the present study, 2,6pipecoloxylidide, an active metabolite of bupivacaine, ${ }^{16}$ was not detected in plasma or in the brain.

\section{Discussion}

In the present study, quinidine reduced the plasma concentration and increased the brain/plasma concentration ratio of bupivacaine at the onset of convulsions. Since quinidine inhibits P-gp activity at plasma concentrations lower than those used in the present study, ${ }^{13,14}$ our results suggest that bupivacaine may be a substrate of P-gp and that inhibition of P-gp by quinidine increased the concentration of bupivacaine in the brain and reduced the plasma concentration of bupivacaine required to induce convulsions. Increased 
Total Bupivacaine

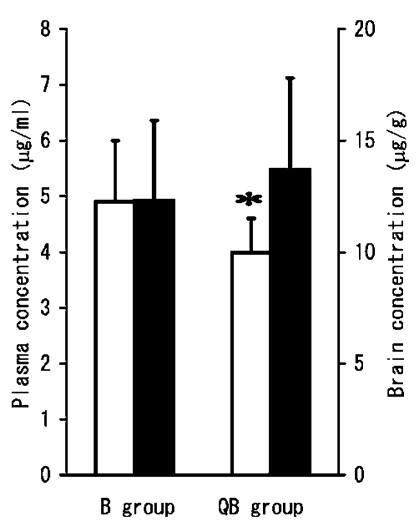

Unbound Bupivacaine

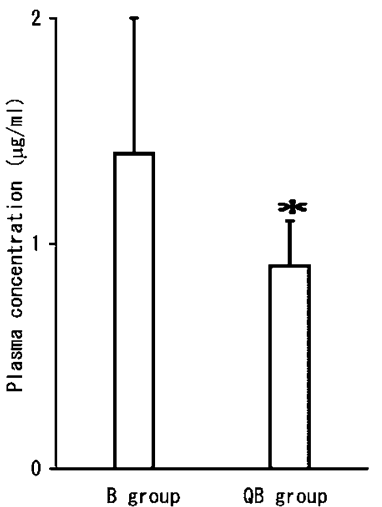

FIGURE 3 Concentrations of total (left) and unbound (right) bupivacaine in plasma and brain at the onset of convulsions in the $\mathrm{B}$ and $\mathrm{QB}$ groups. Open columns = plasma concentration; filled columns $=$ brain concentration. Values are mean \pm standard deviation of ten experiments. ${ }^{*} P<0.05$ vs $\mathrm{B}$ group.

brain/plasma concentration ratio of P-gp substrates as observed in our study has also been reported in mice lacking P-gp compared with wild mice and in animals receiving $\mathrm{P}$-gp inhibitors compared with those without P-gp inhibitors. ${ }^{5,17}$ However, in vitro studies directly showing more accumulation of bupivacaine in cells expressing P-gp than in cells lacking P-gp and/or showing specific binding of bupivacaine to membrane of P-gp-expressing cells, which is reversed by P-gp inhibitor, ${ }^{18}$ will be required to conclude that bupivacaine is a substrate of P-gp.

The CNS toxicity of local anesthetics is influenced by various conditions, such as rate of injection of drugs, MAP, blood $\mathrm{pH}$ and $\mathrm{PaCO}_{2}{ }^{10,19,20}$ In the present study, blood gas data and MAP were comparable between the $\mathrm{L}$ and $\mathrm{QL}$ and between the $\mathrm{B}$ and $\mathrm{QB}$ groups, suggesting that MAP and blood gases had little effect on our results. The convulsive doses and plasma concentrations of bupivacaine at the onset of convulsions were comparable to those noted in a previous report. ${ }^{21}$ The brain/plasma concentration ratio of bupivacaine in the B group at the onset of convulsions was also comparable to that reported by Morishima et al. ${ }^{22}$ Despite the lower plasma concentration of bupivacaine in the $\mathrm{QB}$ group than in the $\mathrm{B}$ group at the onset of convulsions, the cumulative doses of bupivacaine required to induce convulsions were comparable in these two groups. Although the

reason for this discordance in our findings is not clear, ephedrine may have increased cardiac output, resulting in the increased hepatic blood flow and systemic clearance of bupivacaine. The other possible reason is the increased volume of distribution of bupivacaine by quinidine or ephedrine, which may alter its pharmacokinetics. ${ }^{23}$ Quinidine may also affect the protein binding of bupivacaine. However, plasma concentrations of unbound as well as total bupivacaine were lower in the QB group than in the B group at the onset of convulsions, suggesting that alteration of protein binding of bupivacaine did not account for the decreased threshold of plasma concentration for induction of convulsions.

In contrast to bupivacaine, quinidine had no effect on the convulsive dose or concentrations of lidocaine in plasma or brain at the onset of convulsions. Pardridge $e t a l .^{2}$ showed that influx of lidocaine to the brain is not restricted by the blood brain barrier. Pajeva et al. ${ }^{24}$ also reported that lidocaine does not interact with phospholipids constructing tumour cells expressing P-gp. The results of the present study are consistent with these reports. The convulsive dose of lidocaine and the plasma and brain concentrations of lidocaine at the onset of convulsions were similar to those reported previously. ${ }^{10,11}$ There were no differences in the concentration of MEGX, a principal metabolite of lidocaine with convulsive potency, ${ }^{25}$ in plasma or brain between the L and QL groups, either.

Various agents such as calcium channel blockers, coronary vasodilators, quinolines, and cyclosporine have P-gp inhibitory activity. ${ }^{4}$ Of these inhibitors, we used quinidine, since it is often administered chronically for the treatment of arrhythmia and patients receiving quinidine can be given local anesthetics. Although quinidine may decrease MAP and HR, it had no effect on MAP when administered in combination with ephedrine in our experiments. Verapamil and cyclosporine are often used as P-gp inhibitors. However, these agents are also substrates of P-gp and inhibit P-gp activity in a competitive manner, ${ }^{26,27} \mathrm{sug}$ gesting that the degree of inhibition of P-gp depends on the concentration ratio of inhibitors and substrates. The concentrations of these inhibitors required to inhibit P-gp-dependent transport of local anesthetics are unknown, since no data are available regarding the inhibition constants of these inhibitors. Rifampin, an inducer of P-gp may affect the CNS toxicity of bupivacaine, However, rifampin also induces CYP3A, an enzyme responsible for the metabolism of bupivacaine, ${ }^{9}$ might affect the convulsive dose and plasma concentration for inducing convulsions of bupivacaine by increasing the systemic clearance. 
In spite of a large number of reports describing the CNS toxicity of bupivacaine in the clinical setting, ${ }^{28}$ very little information is available regarding the plasma concentration of bupivacaine at the onset of CNS toxicity. Baaijens et al..$^{29}$ reported that the plasma concentrations of total and free bupivacaine in a patient who developed convulsions during cervical epidural analgesia were 6.7 and $1.2 \mu \mathrm{g} \cdot \mathrm{mL}^{-1}$, respectively, which are comparable to our results. Obviously, the results of the present study cannot be extrapolated directly to humans. However, the inhibition of P-gp by quinidine results in respiratory depression by loperamide, which is absent without quinidine, ${ }^{12}$ suggesting that the CNS effects of clinically used P-gp substrates is enhanced by P-gp inhibitors.

In summary, we showed that quinidine reduced the plasma concentration threshold for bupivacaineinduced, but not lidocaine-induced, convulsions in awake rats. Since quinidine is a P-gp inhibitor in humans as well as in animals, our results suggest that the CNS toxicity of bupivacaine should be monitored carefully when a drug with P-gp inhibition activity is used in combination with bupivacaine.

\section{Acknowledgements}

We thank Drs. Hisayo O. Morishima and Masataka Yokoyama for their critical comments.

\section{References}

1 Covino BG. Systemic toxicity of local anesthetic agents (Editorial). Anesth Analg 1978; 57: 387-8.

2 Pardridge WM, Sakiyama R, Fiever G. Transport of propranolol and lidocaine through the rat blood-brain barrier. Primary role of globulin-bound drug. J Clin Invest 1983; 71: 900-8.

3 Juliano RL, Ling V. A surface glycoprotein modulating drug permeability in Chinese hamster ovary cell mutants. Biochim Biophys Acta 1976; 455: 152-62.

4 Krishna $R$, Mayer LD. Multidrug resistance (MDR) in cancer. Mechanisms, reversal using modulators of MDR and the role of MDR modulators in influencing the pharmacokinetics of anticancer drugs. Eur J Pharm Sci 2000; 11: 265-83.

5 Schinkel AH, Wagenaar E, Mol CA, van Deemter L. Pglycoprotein in the blood-brain barrier of mice influences the brain penetration and pharmacological activity of many drugs. J Clin Invest 1996; 97: 2517-24.

6 Wacher VJ, Wu CY, Benet LZ. Overlapping substrate specificities and tissue distribution of cytochrome P450 $3 \mathrm{~A}$ and P-glycoprotein: implications for drug delivery and activity in cancer chemotherapy. Mol Carcinog 1995; 13: 129-34.

7 Oda $\Upsilon$, Furuichi K, Tanaka K, et al. Metabolism of a new local anesthetic, ropivacaine, by human hepatic cytochrome P450. Anesthesiology 1995; 82: 214-20.

8 Imaoka $S$, Enomoto $K$, Oda $\Upsilon$, et al. Lidocaine metabolism by human cytochrome P-450s purified from hepatic microsomes: comparison of those with rat hepatic cytochrome P-450s. J Pharmacol Exp Ther 1990; 255: 1385-91.

9 Gantenbein M, Attolini L, Bruguerolle B, et al. Oxidative metabolism of bupivacaine into pipecolylxylidine in humans is mainly catalyzed by CYP3A. Drug Metab Dispos 2000; 28: 383-5.

10 Yokoyama $M$, Hirakawa $M$, Goto $H$. Effect of vasoconstrictive agents added to lidocaine on intravenous lidocaine-induced convulsions in rats. Anesthesiology 1995; 82: 574-80.

11 Lee VC, Moscicki JC, DiFazio CA. Propofol sedation produces dose-dependent suppression of lidocaineinduced seizures in rats. Anesth Analg 1998; 86: 652-7.

12 Sadeque AJ, Wandel C, He H, Shah S, Wood AJ. Increased drug delivery to the brain by $\mathrm{P}$-glycoprotein inhibition. Clin Pharmacol Ther 2000; 68: 231-7.

13 Fromm MF, Kim RB, Stein CM, Wilkinson GR, Roden $D M$. Inhibition of $\mathrm{P}$-glycoprotein-mediated drug transport. A unifying mechanism to explain the interaction between digoxin and quinidine. Circulation 1999; 99: 552-7.

14 Dautrey S, Felice K, Petiet A, Lacour B, Carbon C, Farinotti $R$. Active intestinal elimination of ciprofloxacin in rats: modulation by different substrates. Br J Pharmacol 1999; 127: 1728-34.

15 Nakamoto T, Oda $\Upsilon$, Imaoka S, Funae $\Upsilon$, Fujimori $M$. Effect of phenobarbital on the pharmacokinetics of lidocaine, monoethylglycinexylidide and 3-hydroxylidocaine in the rat: correlation with P450 isoform levels. Drug Metab Dispos 1997; 25: 296-300.

16 Rosenberg PH, Heavner JE. Acute cardiovascular and central nervous system toxicity of bupivacaine and desbutylbupivacaine in the rat. Acta Anaesthesiol Scand 1992; 36: 138-41.

17 Thompson SJ, Koszdin K, Bernards CM. Opiate-induced analgesia is increased and prolonged in mice lacking $\mathrm{P}$ glycoprotein. Anesthesiology 2000; 92: 1392-9.

18 Callaghan R, Riordan JR. Synthetic and natural opiates interact with P-glycoprotein in multidrug-resistant cells. J Biol Chem 1993; 268: 16059-64.

19 Englesson $S$. The influence of acid-base changes on central nervous system toxicity of local anaesthetic agents I. An experimental study in cats. Acta Anaesthesiol Scand 1974; 18: 79-87.

20 Scott DB. Evaluation of clinical tolerance of local anaesthetic agents. Br J Anaesth 1975; 47: 328-31.

21 Santos AC, DeArmas PI. Systemic toxicity of levobupi- 
vacaine, bupivacaine, and ropivacaine during continuous intravenous infusion to nonpregnant and pregnant ewes. Anesthesiology 2001; 95: 1256-64.

22 Morishima HO, Pedersen H, Finster M, et al. Bupivacaine toxicity in pregnant and nonpregnant ewes. Anesthesiology 1985; 63: 134-9.

23 Thomas JM, Schug SA. Recent advances in the pharmacokinetics of local anaesthetics. Long-acting amide enantiomers and continuous infusions. Clin Pharmacokinet 1999; 36: 67-83.

24 Pajeva IK, Wiese M, Cordes HP, Seydel JK. Membrane interactions of some catamphiphilic drugs and relation to their multidrug-resistance-reversing ability. J Cancer Res Clin Oncol 1996; 122: 27-40.

25 Blumer J, Strong JM, Atkinson AJ Jr. The convulsant potency of lidocaine and its $\mathrm{N}$-dealkylated metabolites. J Pharmacol Exp Ther 1973; 186: 31-6.

26 Schinkel AH, Wagenaar E, van Deemter L, Mol CA, Borst P. Absence of the mdrla P-glycoprotein in mice affects tissue distribution and pharmacokinetics of dexamethasone, digoxin, and cyclosporin A. J Clin Invest 1995; 96: 1698-705.

27 Hendrikse NH, Schinkel AH, De Vries EG, et al. Complete in vivo reversal of P-glycoprotein pump function in the blood-brain barrier visualized with positron emission tomography. Br J Pharmacol 1998; 124: 1413-8.

28 Brown DL, Ransom DM, Hall JA, Leicht CH, Schroeder $D R$, Offord KP. Regional anesthesia and local anesthetic-induced systemic toxicity: seizure frequency and accompanying cardiovascular changes. Anesth Analg 1995; 81: 321-8.

29 Baaijens PF, Gielen MJ, Vree TB, Crul BJ, Jessen HJ. Bupivacaine toxicity secondary to continous cervical epidural infusion. Reg Anesth 1995; 20: 163-8. 